\title{
Magnetic-fluid-based photonic crystal fiber for temperature sensing (Withdrawal Notice)
}

Jin Wa, Muhammad Musavir Bilal, Weihong Bi, Luwen Yang, Xuejing Liu, et al.

Jin Wa, Muhammad Musavir Bilal, Weihong Bi, Luwen Yang, Xuejing Liu, Guangwei Fu, Yanjun Zhang, "Magnetic-fluid-based photonic crystal fiber for temperature sensing (Withdrawal Notice)," Proc. SPIE 11144, Photonics and Education in Measurement Science 2019, 111440N (17 September 2019); doi: $10.1117 / 12.2530879$

SPIE Event: Joint TC1 - TC2 International Symposium on Photonics and Education in Measurement Science 2019, 2019, Jena, Germany 


\section{Magnetic-fluid-based photonic crystal fiber for temperature sensing (Withdrawal Notice)}

Jin Wa, Muhammad Bilal, Weihong Bi, Luwen Yang, Yanshan Univ. (China)

Xuejing Liu, Univ. for Shanghai for Science and Technology (China)

Guangwei Fu, Yanjun Zhang

Yanshan Univ. (China)

Proceedings Volume 11144 , Photonics and Education in Measurement Science 2019; 111440N (2019)

https://doi.org/10.1117/12.2549081

Event: Photonics and Education in Measurement Science 2019, Jena, Germany

Online Publication Date: 17 September 2019

Withdrawn from Publication: 27 February 2020

Publisher's Note: This paper, originally published on 17 September 2019, was withdrawn per author request. 